\title{
"Stuck in the Mud": Limited Employment Success of Persons With Serious Mental Illness in Northeastern Ontario
}

\author{
Karen L. Rebeiro Gruhl \\ Laurentian University \\ Carol Kauppi \\ Centre for Research in Social Justice and Policy, Laurentian University \\ Phyllis Montgomery \\ Laurentian University \\ Susan James \\ Laurentian University
}

\begin{abstract}
Despite policy support, empirical evidence, investment in community mental health programs, and a good deal of rhetoric about promoting recovery, people with serious mental illness (SMI) remain disproportionately represented in paid employment, especially in northern and rural places in Ontario. This study examines access to employment through the perspectives of people with SMI, providers, and decision makers who reside in two northeastern Ontario case communities. A qualitative case study using community-based participatory research methods was employed. Data from interviews conducted with 46 participants were analyzed thematically and were complemented by a secondary data source reporting on the employment outcomes of 4,112 people with SMI. This paper reports on the qualitative findings, highlighting how employment for persons with SMI is stuck in the mud by a dominant community discourse conveying a
\end{abstract}

Karen L. Rebeiro Gruhl, School of Rural and Northern Health, Laurentian University, Sudbury, Ontario; Carol Kauppi, director, Centre for Research in Social Justice and Policy, Laurentian University; Phyllis Montgomery, School of Nursing, Laurentian University, Sudbury, Ontario; Susan James, Midwifery, Laurentian University, Sudbury, Ontario.

The first author would like to acknowledge all the participants of this study, site partners and advisory groups, the policy analysis and research branch of the Ministry of Community and Social Services, especially Aki Telfera, and gratefully, the financial assistance of the Canadian Institutes for Health Research.

Correspondence concerning this article should be addressed to Karen L. Rebeiro Gruhl, Health Sciences North, Community Mental Health and Addictions Program, 127 Cedar Street, $6^{\text {th }}$ Floor, Sudbury, ON P3E 1B1. Email: krebeiro@persona.ca 
disbelief in the capacity of people with SMI to be employed - a discourse sustained by a variety of local and systemic tensions in local practices. This study underscores the ineffectiveness of current employment programs for people who experience SMI in the case communities, and the need to develop local capacity to provide evidence-based practices to improve employment success, and subsequently, to shift marginalizing discourses.

Keywords: mental illness, recovery, employment supports, discourses, beliefs

Employment has long been understood to be a key determinant of health; however, only in the last decade has its importance to mental health and individual recovery received increasing attention in Canadian research and literature (Goering, 2006; Krupa, Kirsh, Gewurtz, \& Cockburn, 2005; Ministry of Health and Long-Term Care, 2001; Ministry of Health and Long-Term Care \& Northeastern Ontario Mental Health Implementation Task Force, 2002; Public Health Agency of Canada, 1999). In Canada, there has been a growing recognition that many aspects of health and social policy have a strong influence on mental health and mental illness, especially policy related to public health, housing, income, education, and employment (Mental Health Commission of Canada, 2009). For people with mental illness, employment is acknowledged to be important to their economic and social well-being, as well as fundamental to their mental and physical health (Crawford, 2004; Razzano et al., 2005).

Employment has been linked to having better social networks, to enhanced quality of life and to overall well-being (Razzano et al., 2005). Yet, despite these health benefits, persons with disabilities in general, and those with serious mental illness (SMI) in particular, continue to experience unacceptably high levels of unemployment and limited participation in the workforce (Crawford, 2004; Mechanic, Bilder, \& McAlpine, 2002; Sudbury Manitoulin Workforce Partnerships Board, 2009). Unemployment rates for people with mental illness have typically been cited as between 75 and 89\% (Mechanic et al., 2002); however, the World Health Organization has suggested that global unemployment rates may be as high as $90 \%$ for persons with SMI (Harnois \& Gabriel, 2000).

In Canada, there has been increasing support for the inclusion of employment in national and provincial policy. In Unison (Federal/Provincial/Territorial Ministers Responsible for Social Services, 1998) provides a Canadian vision of full participation for persons with disabilities. It describes secure and meaningful employment as one of the three building blocks necessary for full citizenship (Wilton, 2006). The report Out of the Shadows (Standing Senate Committee on Social Affairs, Science and Technology, 2006) recommended the establishment of a Canada-wide supported employment program to assist Canadians living with a mental illness in obtaining and retaining employment. In Ontario, the Making It Work policy framework outlined the provision and implementation of an employment supports strategy that reflects evidence-based practices (Ministry of Health and Long-Term Care, 2001).Yet, provincial employment rates for people with SMI remain low, suggesting that employment may not be an integrated component of mental health and recovery programs (Goering, 2006; Koegl, Durbin, \& Goering, 2004; Ontario Technical Advisory Panel, 2007).

In Ontario, $77 \%$ of all persons with mental illness using community mental health services are unemployed (Goering, 2006; Koegl et al., 2004), and needs assessments consistently indicate that assistance 
with employment is often unrecognized by the mental health service provider (Crane-Ross, Roth, \& Lauber, 2000). In northeastern Ontario, for example, employment has consistently been reported as an unmet need of its residents with SMI (Ministry of Health and Long-Term Care \& Northeastern Ontario Mental Health Implementation Task Force, 2002). Research has also indicated that people with SMI who live in rural places are less likely than their cohorts living in urban centres to have access to satisfactory employment services or to become gainfully employed (Gold et al., 2006). However, what the statistics and reports fail to tell us is why people with SMI experience limited employment success, and how this occurs despite a large investment in community mental health teams by the province of Ontario (SEEI Coordinating Centre, 2009), the refinement of best practices for employment (Bond, 2004), and the development of a policy framework for employment (Ministry of Health and Long-Term Care, 2001; SEEI Coordinating Centre, 2009). Bridging this gap was the focus of the present study.

\section{METHODS}

\section{Case Study Design}

A qualitative case study design was used to explore the experience of access to competitive employment for persons who experience SMI within and across two northeastern Ontario communities. The cases were two geographic areas in northeastern Ontario that provide best-practice mental health services, specifically, assertive community treatment and intensive case management services, to persons with SMI. The two case communities were similar in that they provided services in urban and rural places and could be purposively sampled for mental health users, providers, and decision makers involved in service planning and delivery. Where they differed was in the population and geographic size; case community 2 provided services to fewer people overall, to more individuals of francophone heritage, and across a larger geographic area. Sociodemographic information on the communities is provided in Table 1.

Table 1

Demographic Characteristics of Case Communities

\begin{tabular}{lccc}
\hline Demographic characteristics & Case community 1 & Case community 2 & Ontario \\
\hline Population & 192,391 & 120,411 & 12.16 million \\
Geography $\left(\mathrm{km}^{2}\right)$ & 46,476 & 154,527 & $1,000,000$ \\
\% Without high school & 31.3 & 37.6 & 18.7 \\
\% Unemployment rate & 8.4 & 8.2 & 6.4 \\
\% Labour participation rate & 60.8 & 61.9 & 67.1 \\
\% Francophone & 26.4 & 48.2 & 4.1 \\
Economic engines & mining, health care, & mining, forestry, & \\
& farming, tourism & \\
& tourisming & & \\
\hline
\end{tabular}

Source: Statistics Canada 2006 Census Profile, www.Statcan.Gc.Ca 
Community-based participatory research (CBPR) methodology (Israel, Eng, Schulz, \& Parker, 2005) was used to engage key stakeholders in the processes of design, recruitment, entry, and critique of the results. Site partners were secured in each case community, and a consumer advisory body-Northeastern Ontario Network of Consumers - provided ongoing advisement to the research process. Site partners advertised for participants and provided participant contact information to the researcher. Advisory bodies provided input on questions and key stakeholders to include in the study, as well as critical feedback on the final themes and findings. Town hall forums provided feedback on the study findings, and recruited participants for an employment advisory committee to develop an action plan for the study recommendations. The Laurentian University Research Ethics Board granted ethics approval for this study.

\section{Data Collection}

Both quantitative and qualitative data were collected in the larger study. The qualitative data were the primary source of data for this manuscript, complemented by the quantitative data where appropriate. Quantitative data consist of customized statistical tables reporting on the employment outcomes, tenure, earnings, and economic self-sufficiency of persons with SMI who were recipients of the Ontario Disability Income Support Program (ODSP) and who resided in the case communities. All Canadian provinces are responsible for providing disability-related income and employment supports; ODSP is Ontario's venue for providing these services.

Qualitative data collection techniques included (a) individual interviews, (b) group interviews, and (c) field notes. In total, 46 participants who resided in urban or rural places within the case communities were interviewed. Table 2 shows the characteristics of the research participants. Interviews were audiotaped using a digital recorder and were transcribed verbatim. Field notes were written following each interview to reflect the researcher's thoughts about the interview, to describe what was said or observed in the setting, and to serve as a source of information pertaining to the dependability and confirmability of the findings.

\section{Data Analysis}

The qualitative data were examined mainly through inductive analysis; that is, categories of meaning were derived from the data as opposed to imposing a predefined coding system. Transcripts were read several times looking for comments, patterns, or interesting points that stood out in order to answer the research questions of this study. Categories that informed the issues under investigation were amalgamated to form the central themes of the study (Miles \& Huberman, 1994). These themes were further examined for support across all levels of data, as well as across both case communities. Interviewing continued to the point of informational redundancy, whereby further interviews did not contribute new information or insights (Sandelowski, 2000). A preliminary cross-case conceptualization was subjected to feedback from the consumer advisory committee in August 2009, and from site partner agencies in September and October 2009. Member checking was undertaken with all participants involved with the interviews and town hall forums. Names of people, towns, and agencies have been given pseudonyms to ensure confidentiality for respondents. 
Table 2

\section{Characteristics of Participants}

\begin{tabular}{|c|c|c|c|}
\hline $\begin{array}{l}\text { Participant } \\
\text { characteristics } \\
(N=46)\end{array}$ & $\begin{array}{c}\text { Participants } \\
\text { with SMI } \\
n=20\end{array}$ & $\begin{array}{c}\text { Participant } \\
\text { providers } \\
n=18\end{array}$ & $\begin{array}{c}\text { Participant } \\
\text { decision makers } \\
n=8\end{array}$ \\
\hline \multicolumn{4}{|l|}{ Gender } \\
\hline Male & 10 & 6 & 3 \\
\hline Female & 10 & 12 & 5 \\
\hline \multicolumn{4}{|l|}{ Age (yrs.) } \\
\hline $16-24$ & 1 & 1 & 0 \\
\hline $25-35$ & 5 & 4 & 0 \\
\hline $36-45$ & 7 & 7 & 4 \\
\hline $46-64$ & 7 & 6 & 4 \\
\hline \multicolumn{4}{|l|}{ Diagnosis } \\
\hline Schizophrenia & 8 & & \\
\hline Major depression & 5 & & \\
\hline Bipolar disorder & 4 & & \\
\hline Dual diagnosis or concurrent disorder & 3 & & \\
\hline \multicolumn{4}{|l|}{ Age of onset } \\
\hline$<20$ & 9 & & \\
\hline $20-30$ & 8 & & \\
\hline$>30$ & 3 & & \\
\hline \multicolumn{4}{|l|}{ Education level } \\
\hline Some high school & 7 & 0 & \\
\hline High school & 5 & 0 & 0 \\
\hline Some college & 2 & 2 & 1 \\
\hline College or university & 6 & 16 & 7 \\
\hline \multicolumn{4}{|l|}{ Prior work experience } \\
\hline Yes & 20 & & \\
\hline No & 0 & & \\
\hline \multicolumn{4}{|l|}{ Degree of rurality } \\
\hline Rural & 12 & 3 & 1 \\
\hline Urban & 8 & 15 & 7 \\
\hline \multicolumn{4}{|l|}{ Type of income support } \\
\hline ODSP & 14 & & \\
\hline CPP & 3 & & \\
\hline Work/other & 3 & & \\
\hline \multicolumn{4}{|l|}{ Employment status } \\
\hline Unemployed & 13 & & \\
\hline Employed & 7 & & \\
\hline \multicolumn{4}{|l|}{ Experience in Mh or voc (yrs.) } \\
\hline$<5$ & & 4 & 1 \\
\hline $6-10$ & & 6 & 1 \\
\hline $11-20$ & & 8 & 0 \\
\hline$>20$ & & & 6 \\
\hline
\end{tabular}

Note. ODSP $=$ Ontario Disability Support Program; $\mathrm{CPP}=$ Canada Pension Plan; $\mathrm{Mh}=$ mental health; $\operatorname{voc}=$ vocational. 


\section{RESULTS}

In the case communities, participants described access to employment as being "stuck in the mud." The metaphor and verbatim statement of being "stuck in the mud" (Chantal, P-SMI) ${ }^{1}$ is used to conceptually portray the participants' experiences of trying to access employment in northeastern Ontario. The condition of being "stuck" was found to be a consequence of a dominant discourse questioning the capacity of persons with SMI to be employed, and of a variety of local and systemic tensions in everyday practices. We categorized these tensions as rural and northern, jurisdictional, funding related, and organizational. Tensions existed between the ideas governing provincial employment policy for persons with SMI and the ideas, beliefs, and interests embedded in the case communities and reflected in local practices. In short, being stuck echoed what participants had to say about access to employment, and $m u d$, metaphorically, connoted the lack of clarity or muddiness of employment policies and practices within the case communities. The phrase "stuck in the mud" expresses why persons with SMI experience a greater than $91 \%$ unemployment rate in this region of the province (Statistics and Analysis Unit, Policy Analysis and Research Branch, 2009).

\section{How do individuals describe being stuck in the mud?}

Participants offered five explanations for the condition of being stuck in the mud. First, access to employment was primarily limited to the brokered vocational-service-provider model in the case communities. Notwithstanding a recognition of the limited effectiveness of a brokered service model (Ministry of Health and Long-Term Care, 2001), it is the mechanism by which employment support programs in Ontario are provided. Furthermore, most participants engaged the services of a vocational service provider due to the limited participation of the mental health sector in employment services. Participants described employment opportunities as being limited to jobs that their vocational provider needed to fill (i.e., to fulfill their employer contract) as opposed to jobs that were of interest to them. Macias, DeCarlo, Wang, Frey, and Barreiro (2001) found interest to be a strong predictor of competitive employment, which helps to explain the limited employment tenure of participants in this study. While there was some rhetoric that vocational providers were to share jobs and to work together, there was a reluctance to do so because successful job placement was tied to payment. Often, competing interests between vocational providers contributed to persons with SMI being stuck. Lucien (PR) explained how difficult it was to find a job of interest for a client because of the lack of collaboration among vocational providers:

And technically not knowing, like your client could be looking for a, you know, post office job and it could be that one service provider actually has that job, you know, as open right now, and you would never know it. They won't tell you ... they are more business-centred as opposed to client-centred. Yeah, what I kind of mean is like it's a business and they're competing against each other.

Consumer participants described experiencing the following conflicting interests with vocational providers: (a) taking a job that they did not want or were not interested in; (b) participating in extensive "job readiness" training; or (c) risking the loss of the opportunity to access a better job in the future. Ken (P-SMI) identified how people often chose to exit the program because it was easier than remaining trapped in a job they did not like or would not sustain their interest in the long term: 
A lot of people, there was another one had a cleaning job in offices or something from 6 at night till 10 or something and they clean offices and it's entry level and that's the nature of the beast and he did not like that job either and he quit. There is no incentive to keep those jobs, you know what I mean?

Second, participants felt stuck by the lack of mental health system planning for employment. None of the provider participants were able to speak to an organizational plan for employment. As a result, employment services and supports were implemented inconsistently across the case communities. The absence of a plan for employment helps to explain why few decision makers allocated funding for employment services on their mental health teams, and no ACT (assertive community treatment) mental health teams had vocational specialists fully dedicated to employment. Consequently, few providers were able to articulate how they approached employment or whether their practice was based in models designed for people with SMI (Bond, 2004), for example, working collaboratively with the vocational services sector.

A third way participants described being stuck concerned the limited collaboration between mental health and vocational providers. Most providers described being stuck trying to figure out the system on their own and attempting to provide services across a large physical geography without adequate resources to do so. For example, mental health providers described "being stuck using the vocational providers who did not understand the needs of persons with SMI" (Lucien, PR) and whose practices existed primarily outside the jurisdiction of health. Conversely, the vocational providers described being stuck with "a mental health system that provided lip service to employment" (Gisele, VPR). Consumer participants described being stuck having to go back and forth between the vocational and the mental health sector providers, and largely having to assume the burden of collaboration and coordination. Finally, decision makers described being stuck with a policy lacking direction for the implementation of employment services, and with a lack of collaboration between local and provincial interests (Alastair, Monica, DMs). Alastair (DM), for example, identified how the issue of local solutions, a key premise of the regional health authority or Local Health Integration Networks (LHINs) in Ontario, gets bottlenecked at the level of legislation:

The Ministry said hold on a second, there are legislative and policy barriers there and we have to go and look at those now. Yeah, it was a great idea, great idea you know, theoretically, but we have to take a look at that and sometimes they come back to us and say, sorry, we can't do that. We just can't make that change.

The fourth way that employment was perceived to be stuck related to access to employment supportsspecifically, job coaching, training/education, wage subsidies, and long-term support. Currently, access to these supports is tied to the participants' income source, rather than their need. For example, participants who did not receive ODSP did not have the same access to employment supports as ODSP beneficiaries, and participants receiving Canada Pension Plan disability benefits received fewer months of support once employed. Education and training is not the jurisdiction of ODSP, and access to funding for these supports was unclear to most participants.

Fifth, and importantly, the dominant discourse of the mental health provider, team, and organization had a profound impact on consumers' perception of their capacity for employment and to the condition of being stuck. The dominant discourse of the local mental health agency largely determined whether employment was considered a priority for mental health sector resources; whether the organization invested heavily or minimally into employment services; whether time was allocated for the discussion of employment and for 
collaboration; whether an individual was offered access to employment services and supports; and ultimately, whether the individual became employed.

\section{HOW DOES THE DOMINANT DISCOURSE INFLUENCE ACCESS?}

The expression of the dominant discourse could be direct — expressed as stigma or "painting everybody with the same brush"- but more often its expression was indirect, hidden, and less available for public critique. Additionally, participants did not necessarily recognize their comments as discriminatory or marginalizing, but merely as their understanding of the truth. Foucault's (1972) use of the term discourse explains how ideas, attitudes, courses of action, beliefs, and practices can systematically construct the subjects and the worlds of which they speak. Hence, a discourse can influence the production of a belief (e.g., that people with SMI are not capable of competitive employment) and an effect (i.e., the exclusion of persons with SMI from the workforce). As Jason (P-SMI) explained, the community viewed people with SMI as incompetent and incapable of holding down a job: "So, they get it not only by the public, and employment specialiststhere's not even a chance at all. They're considered, honestly, unemployable."

Similarly, Ken (P-SMI) further reflects on how the dominant discourse influences the beliefs of his peers - his comments nicely capturing many of the sentiments expressed in participant interviews:

The problem is that when you get out of the hospital, your doctor says, work, you will never work. Just take the medication and come and see me in 3 months and have a swell life. So the thing is that when you get out of the hospital, if you are lucky and have some support ... your whole life is shattered, you can't work, you can't do this, can't do that, you are on ODSP, instant poverty you know, and there is nothing you can do.

The condition of being stuck in the mud, as a product of the dominant discourse, was evident throughout the interview transcripts and at all informant levels regardless of location. Simone (PR) shared a common belief that persons with SMI are not employable: "A lot of the people that we support here with you know bipolar disorder, schizophrenia, cannot be employed or have a lot of difficulty being employed." Some participants expressed a belief that people with SMI do not want to be employed, and others expressed the belief that individuals with SMI were only capable of part-time or volunteer work: "Usually they work part time. That's the realistic thing" (Angele, PR).

Josée (PR) did not subscribe to the dominant discourse, yet found her practice to be influenced by it. She expressed the frustration of trying to help someone gain competitive employment when the dominant discourse is that volunteer work is the more realistic (or only) option:

You know, because that's what they're being asked to do all the time. You know, volunteer work, volunteer work, volunteer work. And I'm going holy crap, like you know, would you do all that volunteer work? You know, their time is worth money also. You know, changing that attitude that ... [their clients] only can do those jobs. They have to change their attitude at this ... okay, because I think that attitude needs to change. And business attitudes too.... And we need to look at attitudes of the clinical providers as well.

Similarly, Jason (P-SMI) spoke of the systemic contributions to the discourse and to the employment of individuals with SMI:

It starts on all levels, it's, it's at the top, it's the very people that proclaim to help you with employment services have this preconceived attitude that we might be wasting our time with this and it's also with the 
policy makers. It all sounds good on paper but the reality is, is I know a lot of people in [names town] and I can't think of one person who has schizophrenia who is working, and I know at least 30 and a lot of them do want to work.

The final aspect of the discourse concerns four prevalent ideas found to reflect and reproduce the dominant discourse and to sustain the condition of being stuck in the mud: (a) ACT teams are the most efficient and effective way to provide services for persons with SMI in the community; (b) people with SMI require extensive preparation for employment; (c) failure to obtain or keep a job is attributed to the person not being job ready or capable; and (d) a competitive funding model will ensure the best outcomes. These ideas or myths are discussed next.

\section{Myth 1: ACT teams are the most efficient and effective way to provide services.}

Mental health providers used a variety of approaches to foster employment, and many relied on existing models of practice, notably ACT teams. However, most providers spoke of the difficulties of providing employment-related services within an ACT team. Robert (PR), for example, described how despite an overall goal "to integrate their clients within the community," most ACT teams did not consider employment for people with SMI a priority and invested little time in it.

Yes, it takes away our time to actually do recovery-based stuff or goal-focused work with the client because it just comes down to straight maintenance, or keeping them out of hospital, or just doing the basic stuff that really they could be doing on their own and we could have a lot more productive time on our hands otherwise.... Yeah, so sticking with twice-a-day medication drops or daily-drop medication when it really isn't required any more.

\section{Myth 2: People with SMI require extensive preparation for employment.}

A second idea reflecting and reproducing the discourse was a reliance on train-then-place models by vocational providers, conveying a belief in the need for extensive prevocational assessment to determine readiness for work. In everyday practice, most vocational providers identified struggling to help people with a mental illness into employment, and consequently heavily relying upon a variety of prevocational activities and assessments. Many providers shared that they did not perceive people with SMI to be job ready.

Requiring people to participate in extended prevocational preparation created a variety of tensions at the level of service provision, as well as contributing to the dominant discourse by reinforcing the belief that people with SMI require extensive preparation to become employed. Prevocational activities limited access to employment because placement was not rapid; work is often a "trial" before participants are paid or offered employment, and often, several weeks or months elapse between signing on with a vocational provider and finding paid employment (some participants waited up to 8 months). Consequently, many participants stopped attending, lost interest, or simply quit. A focus on prevocational preparation limited the providers' ability to capitalize on the individual's interest in working - especially important for individuals who may experience difficultly with motivation or who lose interest quickly due to the nature of their illnesses. According to Robert, a northern provider, "From my experience, we never got to the work part. They always did the training and non-paid work and hands-on training and then once their placement was over, unfortunately, like I said earlier, it [employment] did not materialize." 


\section{Myth 3: Failure to obtain or keep employment is a personal failure.}

A third idea reflecting and reinforcing the discourse concerned the routine manner in which individuals with SMI were blamed for any employment failure. Few providers recognized their own practices of providing employment services as problematic or responsible for poor outcomes. Instead, the individual with SMI was most often blamed for not being "employment ready," not being suitable for competitive employment, or not wanting to work. Where the individual was not directly implicated, the mental health sector often blamed the vocational service sector for not providing appropriate services for persons with SMI. Vocational providers in turn blamed the mental health sector for not participating more in the employment of persons with SMI.

\section{Myth 4: A competitive funding model will ensure the best outcomes.}

The final idea reproducing the discourse is that a competitive funding model will foster better employment outcomes for people with SMI; however, this has not been realized in the case communities. The ODSP funding model is outcome based, with funding to programs based on preset targets (defined as 13 weeks of cumulative employment). Vocational providers often get stuck between knowing the importance of job coaches and supports to the employment success of people with SMI, and the reality that the agency will not be paid if the client does not last to the job-retention target. Mathieu (VPR) viewed the ODSP funding model as ineffective for working with people with disabilities and, in particular, blamed it for not funding necessary supports:

It absolutely doesn't work anymore.... ODSP employment service ... okay? They have created ways of not paying us - we found 96 jobs, we got paid for 40 , very clever ways of not paying us. We're not getting paid for half the work we're doing.... So there's no money there to work with disabled people anymore, okay?

A voiced lack of confidence that people with SMI will achieve the 13-week target contributed to the discourse and to providers not wanting to commit funds to employment supports and services, or doing so reluctantly. A vicious cycle was created in which employment supports became regarded as a financial disincentive to working with people with SMI since providing for them essentially subtracts from the providers' economic bottom line. Since these training and support costs are paid out-of-pocket by the vocational service agency and only recovered if the individual successfully meets the 13-week target, further tensions are created related to competition, both for people with SMI and for other vocational providers who are competing for the same individuals, employers, and jobs.

\section{DISCUSSION}

In this study, consumer, provider, and decision-maker participants described how despite a strong policy intention to promote the employment of persons with SMI, few are employed in northeastern Ontario. Previously, northern research has identified how rural and northern places receive fewer resources to provide the same services over large areas (DesMeules et al., 2006; Pong \& Russell, 2003). Research participants voiced concern about the limited resources dedicated to employment. Lack of collaboration across agencies was an important finding. Employment success has also been tied to the availability of context-specific supports (Becker, Xie, McHugo, Halliday, \& Martinez, 2006), to the types and quantity of employment available 
(e.g., mining and forestry versus retail and manufacturing), and to the availability of secondary labour market opportunities for persons with SMI (lower paying jobs with no benefits or security; Wilton, 2004, 2006). Typically, people residing in northern and rural Ontario communities do experience higher unemployment than other regions of the province (North East LHIN, 2008); however, Salkever et al. (2007) demonstrated that places experiencing high unemployment did not necessarily result in lower employment opportunity for persons with SMI. Instead, Salkever identified that the secondary labour market was fairly resilient in economic downturns and did not reflect the primary labour market as previously understood. According to Salkever, the belief that low market economies are associated with low employment opportunity for persons with SMI is largely unfounded.

Another issue concerns the reliance on ACT teams for the provision of mental health services in northern and rural places despite their limited success with employment provincially (Lurie, Kirsh, \& Hodge, 2007; Ontario Technical Advisory Panel, 2007). Meyer and Morrissey (2007) found that improving employment participation in rural places was challenging for ACT teams. They reported that it is difficult for rural ACT teams to maintain fidelity to specific standards because they have been forced to make several adaptations to the model, including smaller teams, less comprehensive staff, and less intensive services. Critics of the ACT model emphasize its limited success in enabling higher-order aspects of community integration, such as mainstream employment (Gomory, 2005). Participants in this study echoed similar sentiments; employment was not offered to all participants as a standard of care, and decision makers acknowledged that employment was a low priority. Given that ACT teams are considered to be one of the primary service-delivery vehicles for integrating individuals with SMI into Ontario communities (Horgan, 2007), their lack of success with employment and difficulty with model fidelity in rural places raises the question: Is ACT the best model for employment?

Notwithstanding the above, the participants consistently attributed their limited employment success to the attitudes, beliefs, and preconceived notions that they experienced in everyday practices - pointing to the existence of a larger discourse that all people with SMI lacked capability for competitive employment. Consequently, any lack of employment success was often attributed to individual deficits (e.g., SMI), or to a lack of desire to work - the latter easily disputed by previous needs assessments. A reluctance by individual providers to acknowledge any contribution to the low employment success is unsettling, especially given their voiced hesitancy to undertake employment-related activities in the mental health sector, and to work with people with SMI in the vocational services sector. Foucault (1972) emphasized how societal discourses influenced the construction of current truths in society, their role in legitimating ideas and interests, and the power these ideas contain. In this sense, a discourse is something that produces something else (an utterance, a concept, an effect, a belief), rather than something that exists in and of itself and can be analyzed in isolation (Mills, 1997). In the case communities, the dominant discourse contributed to the construction of a local truth or belief about people with SMI that did not include mainstream employment. It also underscored a variety of practices in the case communities known to be antithetical to evidence-based supported employment practices (e.g., limited encouragement of competitive employment, use of extensive prevocational assessment and preparation; Bond, 2004). According to Gowdy, Carlson, and Rapp (2004), prevocational preparation is an idea and an approach incompatible with best practices for persons with SMI, reflecting a belief that consumers need to move through various stages of vocational programming prior to being ready 
for competitive employment. Gowdy et al. studied organizational factors that fostered best employment outcomes for people with SMI, and noted that programs that did not focus on prevocational activities possessed a higher opinion of the abilities of their consumers than did the comparison sites, and achieved better employment outcomes. In the present study, participants reported the regular use of prevocational activities to determine the job readiness of people with SMI. A belief in a lack of job readiness was strongly conveyed in service-provider interviews, and served to support the use of prevocational assessments. Angele (PR), for example, noted that "clients with mental health, we have to get them to reality. We always do a work trial to make sure they will show up and be on time."

The dominant discourse was prevalent in both case communities - and informed those very practices funded to assist people into employment. The ideas reflected and reproduced by this discourse served to limit access to employment programs, services, funding, and opportunity for persons with SMI in the case communities. According to Link and Phelan (2006), "what matters is whose cognitions prevail—whose cognitions carry sufficient clout in social, cultural, economic, and political spheres to lead to important consequences for the group that has been labeled as different" (p. 378). In the case communities studied, the prevailing cognitions did not support competitive employment for people with SMI-these local truths being sufficiently pervasive and rarely contested. The resulting discourse serves as a starting point for understanding why employment success is low in northeastern Ontario, and helps to explain why people with SMI are stuck in the mud.

\section{Strengths and Limitations of the Study}

One strength of this study is its grounding in a community-based participatory approach to the various stages of the research through the inclusion of persons who experience SMI: They were involved in shaping the focus of the study and research questions, identifying key informants, and in critiquing, endorsing, and disseminating study results. The participation of key site partner agencies in each of the case communities is a second strength. The Canadian Mental Health Association, the Employment Supports branch of the Ontario Disability Support Program, and the Northeastern Ontario Network of Consumers made it possible to include the voices of many individuals throughout a large geographic area. Additionally, these site partner agencies provided invaluable endorsement of the study findings, notwithstanding some discomfort in learning of them. In total, 95 individuals and five advisory bodies endorsed the findings of the study. A final strength of the study is the use of multiple methods and participants to examine the issue of access to employment from multiple levels, locations, and perspectives of the mental health system across a large geographic re-

gion such as northeastern Ontario. The involvement of site partners helped to bridge the geography for the researcher and to reduce investigator recruitment bias by assisting with obtaining broad-based participation, in particular, of rural participants.

The limitations of the study include the fact that the principal investigator did not speak French. A second limitation is the lack of Aboriginal participation, especially given that approximately 7 to $10 \%$ of the northeastern Ontario population is Aboriginal (North East LHIN, 2008). Third, the findings are limited to the case communities studied. 


\section{CONCLUSIONS}

This paper draws from a larger study exploring access to employment for persons with SMI who reside in northern and rural places. The study reveals how the current approach to the employment of persons with SMI is neither effective nor efficient - less than $9 \%$ experience any employment participation and fewer are keeping their jobs. A dominant discourse that questions the capacity of people with SMI to become competitively employed, and the systemic and local tensions that arise from practices grounded in this discourse contributed to the low employment success in the case communities. The need to build local capacity to provide evidence-based supported employment is underscored - not only to promote work as an aspect of mental health recovery and to improve local employment success, but also to remove the burden for failure to be employed from people with SMI. The study also draws attention to the need for collaboration among mental health and vocational providers to address the challenges faced by limited resources and a large geography in the case communities, as a principle of evidence-based practice and as a means of improving system efficiency. Future research might explore whether building local capacity to provide evidence-based supported employment can influence the larger discourse, enhance collaboration, and subsequently, employment success in northern communities.

\section{NOTE}

1. P-SMI refers to an individual with SMI, PR to a mental health provider, VPR to a vocational service provider, and DM to a decision maker participant.

\section{RÉSUMÉ}

Malgré le soutien politique, des preuves empiriques, les investissements dans les programmes communautaires de santé mentale, et une bonne partie de la rhétorique sur la promotion du rétablissement, les personnes atteintes de maladie mentale grave $(\mathrm{MMG})$ restent surreprésentées dans les emplois rémunérés, surtout dans les régions nordiques et rurales de l'Ontario. Afin d'examiner l'accès à l'emploi à travers les perspectives des personnes atteintes de MMG, les fournisseurs et les décideurs qui résident dans deux collectivités du Nord-est de l'Ontario. Cette recherche est une étude de cas qualitative utilisant des méthodes de recherche participatives communautaires. Les données provenant des entrevues avec 46 participants ont fait l'objet d'analyses thématiques et ont été complétées par une source de données secondaires sur les résultats en matière d'emploi de 4112 personnes atteintes de MMG. Cet article présente les résultats qualitatifs de l'étude qui mettent l'accent sur combien l'emploi pour les personnes MMG est « coincé dans la boue » par un discours de la communauté dominante. Ce discours véhicule une incrédulité dans la capacité d'employabilité des personnes atteintes de MMG et est soutenu par une variété de tensions locales et systémiques existant au sein des pratiques locales. Cette étude souligne l'inefficacité des programmes d'emploi actuels pour les personnes qui souffrent de maladies mentales graves dans les communautés étudiées et de la nécessité de développer les capacités locales pour fournir des pratiques fondées sur des données probantes pour améliorer la réussite sur le plan de l'emploi et, ensuite, de modifier les discours qui marginalisent.

Mots clés : maladie mentale, rétablissement, supports à l'emploi, discours, croyances 


\section{REFERENCES}

Becker, D. R., Xie, H., McHugo, G. J., Halliday, J., \& Martinez, R. A. (2006). What predicts SE program outcomes? Community Mental Health Journal, 42(3), 303.

Bond, G. R. (2004). SE: Evidence for an evidence-based practice. Psychiatric Rehabilitation Journal, 27(4), 345.

Crane-Ross, D., Roth, D., \& Lauber, B. G. (2000). Consumers' and case managers' perceptions of mental health and community support service needs. Community Mental Health Journal, 36(161), 178.

Crawford, C. (2004). Improving the odds: Employment, disability and public programs in Canada. North York, ON: L'Institut Roeher Institute.

DesMeules, M., Pong, R., Lagacé, C., Heng, D., Manuel, D., Pitblado, R., ... Koren, I. (2006). How healthy are rural Canadians? An assessment of their health status and health determinants, summary report. Ottawa, ON: Canadian Institute for Health Information.

Federal/Provincial/Territorial Ministers Responsible for Social Services. (1998). In Unison: A Canadian approach to disability issues (Cat. No. MP43-390/1998E). Ottawa, ON: Human Resources Development Canada.

Foucault, M. (1972). Archaeology of knowledge. New York, NY: Pantheon.

Goering, P. (2006). Making a difference: Ontario's community mental health evaluation initiative. Toronto, ON: Canadian Mental Health Association. Retrieved from http://www.Ontario.cmha.ca/cmhei/images/report/ Making_a_Difference.pdf

Gold, P. B., Meisler, N., Santos, A. B., Carnemolla, M. A., Williams, O. H., \& Keleher, J. (2006). Randomized trial of supported employment integrated with assertive community treatment for rural adults with severe mental illness. Schizophrenia Bulletin, 32(2), 378-395.

Gomory, T. (2005). Assertive community treatment (ACT): The case against the "best tested" evidence-based community treatment for severe mental illness. In S. A. Kirk (Ed.), Mental disorders in the social environment: Critical perspectives (pp. 165-189). New York, NY: Columbia University Press.

Gowdy, E. A., Carlson, L. S., \& Rapp, C. A. (2004). Organizational factors differentiating high performing from low performing SE programs. Psychiatric Rehabilitation Journal, 28(2), 150.

Harnois, G., \& Gabriel, P. (2000). Mental health and work: Impact, issues and good practices. Geneva, Switzerland: World Health Organization, International Labour Organization.

Horgan, S. (2007). Tracing the tensions, constructions, and social relations surrounding community integration practice for individuals with severe mental illness: A focus on assertive community treatment (Doctoral thesis, Queen's University, Kingston, Ontario).

Israel, B. A., Eng, E., Schulz, A. J., \& Parker, E. A. (Eds.). (2005). Methods in community-based participatory research for health. San Francisco, CA: Jossey-Bass.

Koegl, C., Durbin, J., \& Goering, P. (2004). Mental health services in Ontario: How well is the province meeting the needs of persons with serious mental illness? Analysis of data collected during the provincial psychiatric hospital and community comprehensive assessment projects (No. 2923/03-04). Toronto, ON: Health Systems Research and Consulting Unit, Centre for Addiction and Mental Health.

Krupa, T., Kirsh, B., Gewurtz, R., \& Cockburn, L. (2005). Improving the employment prospects of people with serious mental illness: Five challenges for a national mental health strategy. Canadian Public Policy, 31(Suppl., October): S59-63.

Link, B. G., \& Phelan, J. C. (2006). Stigma and its public health implications. The Lancet, 367(9509), 528-529.

Lurie, S., Kirsh, B., \& Hodge, S. (2007). Can ACT lead to more work? The Ontario experience. Canadian Journal of Community Mental Health, 26(1), 161-171.

Macias, C., DeCarlo, L. T., Wang, Q., Frey, J., \& Barreiro, P. (2001). Work interest as a predictor of competitive employment: Policy implications for psychiatric rehabilitation. Administration and Policy in Mental Health, 28(4), 279.

Mechanic, D., Bilder, S., \& McAlpine, D. D. (2002). Employment of persons with serious mental illness. Health Affairs, 21(5), 242-253. Retrieved from http://proquest.umi.com/pqdweb?did=187443921\&Fmt=3\&clientId=22643\&R $\mathrm{QT}=309 \& \mathrm{VName}=\mathrm{PQD}$

Mental Health Commission of Canada. (2009). Towards recovery and well-being: A draft framework for a mental health strategy for Canada. Ottawa, ON: Author. Retrieved from http://www.mentalhealthcommission.ca/ SiteCollectionDocuments/Key_Documents/en/2009/Mental_Health_ENG.pdf 
Meyer, P., \& Morrissey, J. (2007). A comparison of assertive community treatment and intensive case management for patients in rural areas. Psychiatric Services, 58(1), 121-127.

Miles, M. B., \& Huberman, A. M. (1994). Qualitative data analysis: An expanded sourcebook (2nd ed.). Thousand Oaks, CA: Sage Publications.

Mills, S. (1997). Discourse. London, UK: Routledge.

Ministry of Health and Long-Term Care. (2001). Making it work: Policy framework for employment supports for people with serious mental illness (Policy framework No. 7610-4232419). Toronto, ON: Queen's Printer. Retrieved from http://www.health.gov.on.ca/english/public/pub/mental/pdf/pfes_e.pdf

Ministry of Health and Long-Term Care \& Northeastern Ontario Mental Health Implementation Task Force. (2002). The time for change is now: Building a sustainable system of care for people with mental illness and their families in the northeast region. Employment and education. Toronto, ON: Queen's Printer. Retrieved from http://www. health.gov.on.ca/english/providers/pub/mhitf/north_east/sec_7.pdf

North East LHIN. (2008). Population profile at a glance: NE LHIN. Retrieved from http://www.nelhin.on.ca/Page. aspx?id=4024

Ontario Technical Advisory Panel. (2007). 2005/06 Ontario ACT data outcome monitoring report. Toronto, ON: Ministry of Health and Long-Term Care.

Pong, R. W., \& Russell, N. (2003). A review and synthesis of strategies and policy recommendations on the rural health workforce. Sudbury, ON: Centre for Rural and Northern Health Research.

Public Health Agency of Canada. (1999). Towards a healthy future: Second report on the health of Canadians (No. H39468/1999E). Ottawa, ON: Health Canada.

Razzano, L. A., Cook, J. A., Burke-Miller, J. K., Mueser, K. T., Pickett-Schenk, S. A., Grey, D. D., . . Carey, M. A. (2005). Clinical factors associated with employment among people with severe mental illness: Findings from the employment intervention demonstration program. Journal of Nervous and Mental Disease, 193(11), $705-713$.

Salkever, D., Karakus, M., Slade, E., Harding, C., Hough, R., Rosenheck, R., ... Yamada, A. (2007). Measures and predictors of community-based employment and earnings of persons with schizophrenia in a multisite study. Psychiatric Services, 58(3), 315-324.

Sandelowski, M. (2000). Focus on research methods: Combining qualitative and quantitative sampling, data collection, and data analysis techniques in mixed-method studies. Research in Nursing \& Health, 23, 246.

SEEI Coordinating Centre. (2009). Moving in the right direction: SEEI final report. Toronto, ON: Health Systems Research and Consulting Unit, Centre for Addiction and Mental Health. Retrieved from https://www.ehealth Ontario.ca/portal/server.pt/gateway/PTARGS_0_11862_11867_1402_14497_43/http\%3B/ptpublisher.phportal. srv.ehealthOntario.ca\%3B7087/publishedcontent/publish/ssha/eho/communities/mental_health_and_addictions/ systems_enhancement_evaluation_initiative/final_reports/seei_final_report_web.pdf

Standing Senate Committee on Social Affairs, Science and Technology. (2006). Out of the shadows at last: Transforming mental health, mental illness and addictions services in Canada. Ottawa, ON: Government of Canada.

Statistics and Analysis Unit, Policy Analysis and Research Branch. (2009). Characteristics of ODSP adult beneficiaries with mental disorders in northern Ontario. Toronto, ON: Social Policy Development Division, Ministry of Community and Social Services.

Sudbury Manitoulin Workforce Partnerships Board. (2009). 2009 TOP report (Vol. 2, Issue 2). Sudbury, ON: Author. Wilton, R. (2004). Putting policy into practice? Poverty and people with serious mental illness. Social Science and Medicine, 58(1), 25-39.

Wilton, R. (2006). Working at the margins: Disabled people and the growth of precarious employment. In D. Pothier \& R. Devlin (Eds.), Dis-ability. Critical disability theory: Essays in philosophy, politics, policy and law (1st ed., pp. 130-150). Vancouver, BC: UBC Press. 